\title{
The Ph.D. Track: Who Succeeds, Who Drops Out?
}

\author{
Hans Groenvynck*, Karen Vandevelde**, Ronan Van Rossem*** \\ *Hans.Groenvynck@UGent.be \\ ECOOM, Department of Sociology, Ghent University, Korte Meer 3, Ghent, 9000, Belgium.
}

**Karen.Vandevelde@UGent.be

ECOOM, Department of Research Affairs, Ghent University, Sint-Pietersnieuwstraat 25, Ghent, 9000, Belgium

***Ronan.VanRossem@UGent.be

Department of Sociology, Ghent University, Korte Meer 3, Ghent, 9000, Belgium.

\begin{abstract}
Doctoral completion rates are an indicator of successful doctoral programmes and of a region's potential of highly skilled workforce. The Human Resources in Research - Flanders (HRRF) database contains data of all academic staff appointments, doctoral student registrations and doctoral degrees of all Flemish universities from 1990 on. Previous research has identified the following factors as affecting successfully completing the Ph.D.: cohort, scientific discipline, type of scholarship or appointment, gender, age and nationality. We present a competing risk analysis of factors determining Ph.D. completion and drop-out. This event history technique allows for determining the relative impact of each of these characteristics on the level of success/failure $\&$ time to degree. It predicts at what time periods the 'time to degree' and 'time till drop out' is most likely to occur, and why some individuals experience the event earlier than others. Our results show that scientific discipline and funding situation are the most important factors predicting success in obtaining the doctorate degree.
\end{abstract}

\section{Introduction}

Completion rates and time to degree in doctoral training programmes are important indicators monitoring the stock and flow of researchers in the academic labour market and in evaluating the efficiency and effectiveness of doctoral education (Larivière, 2012; Visser, Luwel, \& Moed, 2007; Wright \& Cochrane, 2000). The return-on-investment in doctoral education is negatively affected by high attrition, low completion and a long time to degree (Wao, 2010; Tuckman, Coyle, \& Bae, 1990), both from a cost-effective economic point of view (i.e. the funder, organiser and supervisor of the doctoral programme as main stakeholders) as from an effective career path perspective (i.e. the individual researcher's postdoc and further career options).

ECOOM-UGent, Flanders' Centre for R\&D Monitoring at Ghent University keeps track of all academic staff appointments, doctoral student registrations and doctoral degrees of the five Flemish universities from 1990 on, in the Human Resources in Research - Flanders (HRRF) database. Although the HRRF database contains administrative data primarily designed for policy-relevant monitoring, analyses of its contents allow for an improvement upon earlier studies of the determinants of doctoral outcomes (success, failure and the time until either of the two) because of a number of reasons: 
(1) The dataset contains the full population, not samples, of researchers at each of the five Flemish universities, an improvement upon earlier studies focused on data from merely one institution (e.g., Ampaw \& Jaeger, 2011; Ehrenberg \& Mavros, 1995; Wao, 2012; Wright \& Cochrane, 2000), or studies largely dependent on survey responses (e.g. Hoffer \& Welch, 2006; Seagram, Gould \& Pyke, 1998).

(2) All research fields are taken into account, allowing for fine-grained comparisons across and between fields rather than focusing on one or only a few disciplines (e.g. Ehrenberg \& Mavros, 1995; Espenshade \& Rodriguez, 1997; Seagram, Gould \& Pyke, 1998; Wao, 2012). (3) As the data contain full appointment information, analyses can go further than studying merely the occurrence of completion (e.g. Ampaw \& Jaeger, 2011) or the actual time of completion (e.g. Mastekaasa, 2005, Wao, 2010); and also include time-to-drop-out.

(4) This is linked to an additional advantage: as the appointment information corresponds with 'sponsored time', excluding periods of unemployment, illness or leave of absence, time to degree/drop-out can be calculated using not only the calendar-based approach between admission and completion/drop-out but also the 'sponsored time' approach covering the actual funded period.

(5) Finally, due to the large sample in the database and continuous updating, analyses can control for evolutions over time and as such might assess the impact of policy decisions or economic/educational changes at anyone point in time.

This paper studies the determinants of doctoral success and failure using the administrative data available in the HRRF database. Previous research identified the following characteristics as having an impact on doctoral success, on failure as well as on the time required to complete the doctoral degree.

- Scientific discipline: Espenshade \& Rodriguez (1997) ; Seagram, Gold \& Pyke (1998) as well as Wright and Cochrane (2000) all found that timely doctoral completions vary significantly by discipline. Despite some variation in subfields, students in natural sciences are more likely to complete their $\mathrm{PhD}$, and often faster, than those in arts and humanities.

- Funding and type of scholarship: Students with scholarships are most likely to complete, and complete faster, compared to teaching assistants and self-supporting students (Ehrenberg \& Mavros, 1995). No other studies have examined the impact of different types of scholarships.

- Gender: While Seagram, Gold \& Pyke (1998) did not find significant gender differences in time to degree when controlling for other variables such as scientific discipline at a Canadian university, two other studies do observe differences. Wao's (2010) study of completion rates at a large college in the U.S shows faster completion by females while Mastekaasa (2005) in Norway suggests slightly faster completion by males.

- Nationality: Espenshade \& Rodriguez (1997) found that foreign students in the US outperform their 'native' counterparts: slightly higher fractions complete the Ph.D. (54 versus 50 percent), and the average completion time for the former is about one year less than for the latter.

- Age: Wright and Cochrane (2000) compared the percentage of successful Ph.D. submission within four years between two age groups (20-26 years and 27-75 years), based on their age at registration. They found that the youngest age group demonstrated higher completion rates and shorter time-to-degree.

- Cohort: Doctoral attainment can be expected to have changed over time, just as educational attainment at BA and MA level has (Bradley, 2000). In most doctoral attainment studies, comparisons of cohorts have not been included. However, Hoffer 
and Welch (2006) observed an increase in time to degree of 1.1 year between 1978 and 2003.

In this paper, first the determinants of doctoral outcomes (success and dropping out) are studied separately. While all these factors have some impact, none of the above studies examined the interplay of these characteristics. In order to address the 'combined risk' of obtaining the doctoral degree or dropping out we perform a competing risk analysis of factors determining Ph.D. completion and drop-out. The joint impact of these characteristics on the speed of success and drop-out is studied, which allows for an identification of those characteristics that have the biggest impact on doctoral outcomes.

\section{Determinants of doctoral outcomes}

First, success and failure indicators are discussed separately. Parameters that are indicative of success or failure are completion rates within a period of eight years (success rate) and the degree of drop out within eight years (drop-out rate). Although funding for doctoral training is generally limited to 4 years full-time or 6 years part-time, 8 years is considered an adequate period to assess success or failure - both indicators of effectiveness. Additionally, also indicators of efficiency are relevant: the median and mean sponsored time until attaining a doctoral degree (FTTD).

In Flanders, most Ph.D. students are considered full professionals with salary-level bursaries or staff appointments, while also enjoying student status. Some combine temporary research contracts to fund their doctoral training period. The analyses in this paper are based on the actual "sponsored" or "financed" time of these junior researchers between the first academic position or start of the doctoral degree at a Flemish university, and the completion of the doctoral career track (i.e. moment of dropping out or completing the doctorate), minus periods of 'absence' during and between appointments - illness, temporary unemployment, etc. The small group of $\mathrm{Ph} . \mathrm{D}$. students who do not receive funding through the university system, are not included in this analysis focusing on 'sponsored' time only.

For every year being observed, all junior researchers in the HRRF database are assigned one out of three statuses: (1) still active, (2) success (Ph.D. attained) or (3) dropped out. A doctoral student completing 4.3 years after starting the doctoral degree, will be registered as 'still active' in year 4 and 'success' in year 5.

As argued above, we examine the following characteristics as possible determinants of doctoral outcomes: cohort, scientific discipline, type of scholarship or appointment, gender, age and nationality.

Three cohorts (defined by the entry year as junior researcher) are distinguished: those who entered in the academic years 1990-1996 (cohort 1) will be compared to those who entered in 1997-2003 (cohort 2) and 2004-2008 (cohort 3).

All research fields are grouped into five scientific disciplines: (1) medical sciences, (2) humanities, (3) social sciences, (4) applied sciences and (5) natural sciences.

The range of doctoral scholarships and research appointments are clustered into five categories. Researchers moving from one category to another during their junior research career are assigned to a "dominant category" on the basis of a decision chart reflecting the hierarchies between these categories: (1) assistant lectureships, which allow researchers to spend on average $50 \%$ of their time on research and $50 \%$ on teaching, (2) competitive scholarships awarded by Flemish funding bodies, (3) competitive scholarships from the home university, (4) appointments based on project funds for fundamental research and (5) appointments based on other project funds, usually for applied research, and often lasting less than 4 years. 
Age is determined as the age at the time of the first 'academic appointment' in the university: registration as a doctoral researcher, scholarship commencement, or appointment as research staff. Five age categories are used: (1) younger than 26, (2) 26-30, (3) 31-35, (4) 36-40, and (5) 41 and older.

Regarding nationality, junior researchers are attributed to one of three categories: (1) Belgian nationals, (2) nationals from another EU country and (3) non-EU nationals.

\section{Descriptive analysis of doctoral success and time to degree}

Amongst the 28,871 junior researchers being analysed, the median sponsored time to degree is 4.5 years. Within a period of eight years of funding, $47.4 \%$ attain a Ph.D. and $49.9 \%$ drop out. The cumulative success and drop-out rates, as well as the relative number of junior researchers being 'still active' are plotted in Figure 1. While most drop-out occurs during the first five years, acquiring a $\mathrm{Ph}$.D. rarely takes place before the fourth financed year.

Cumulative degrees of success and drop-out are plotted over the first eight years of sponsored time in order to illustrate the relation between the amount of and time till success. Drop-out rates are not discussed in detail in the descriptive analyses but they will be included in the competing risk analysis.

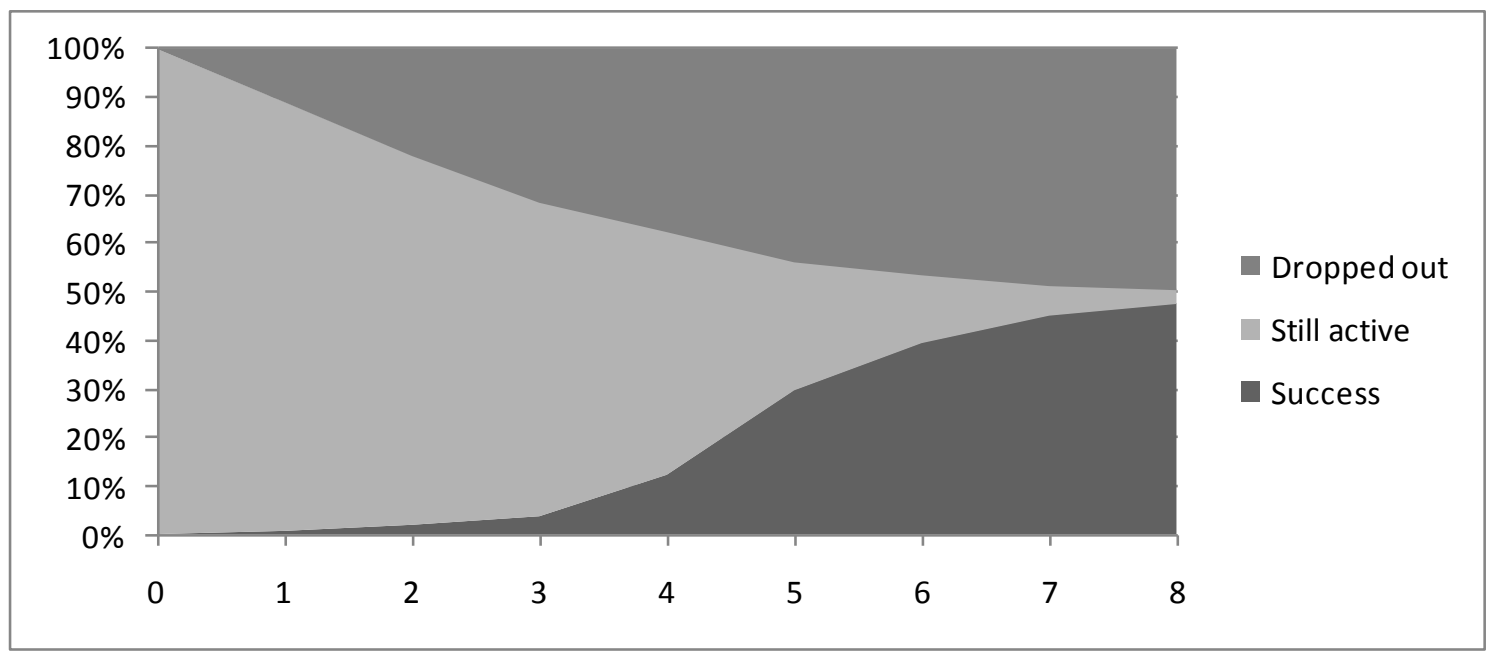

Figure 1: Status of junior researchers within 8 years of sponsored time

\section{Cohort}

Junior researchers belonging to the second cohort perform better than junior researchers from the first cohort (see Table 1$)$, both with regard to sponsored time to degree $(0.39$ years shorter median FTTD), success rate (10.7 percentage points more Ph.D.'s within eight years) and drop-out rate (7.6 percentage points less drop out within eight years). The third cohort is incomplete, therefore the shorter time to degree is an artefact.

Table 1: Indicators by cohort: sponsored time to degree, success and drop-out rate

\begin{tabular}{lrccccc}
\hline & $\mathrm{N}$ & $\begin{array}{c}\text { Median } \\
\text { (FTTD) }\end{array}$ & $\begin{array}{c}\text { Mean } \\
\text { (FTTD) }\end{array}$ & $\begin{array}{c}\text { SD } \\
\text { (FTTD) }\end{array}$ & $\begin{array}{c}\text { Success rate } \\
\text { (after 8 } \\
\text { years) }\end{array}$ & $\begin{array}{c}\text { Drop-out } \\
\text { rate (after 8 } \\
\text { years) }\end{array}$ \\
\hline $1990-1996$ (cohort 1) & 7,379 & 4.89 & 5.15 & 2.00 & $41.5 \%$ & $53.3 \%$ \\
$1997-2003$ (cohort 2) & 11,857 & 4.48 & 4.59 & 1.39 & $52.2 \%$ & $45.7 \%$ \\
$2004-2009$ (cohort 3) & 9,635 & 3.93 & 3.65 & 0.92 & $/$ & $/$ \\
\hline
\end{tabular}


The cumulative success rates according to cohort are presented in Figure 2. With regard to success rate, the difference in percentage points between the first two cohorts after five years is already $9.8 \%$, and between the first and third cohort $16.8 \%$.

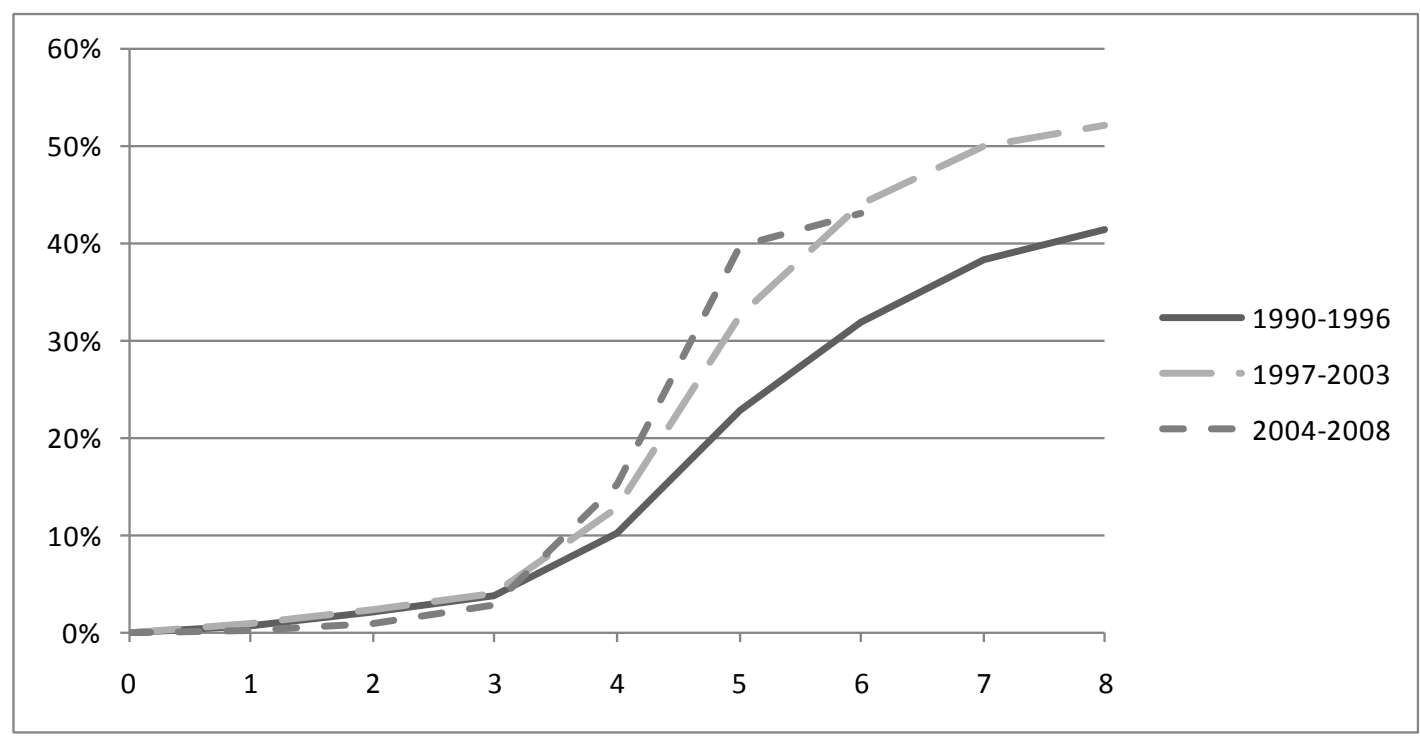

Figure 2: Cumulative success rates within a period of eight years of sponsored time, by cohort

\section{Scientific Discipline}

The variation in median FTTD amongst scientific domains is high, amounting to .68 year (see Table 2). The success and drop-out rates after eight years also show large differences, $33.0 \%$ and $32.9 \%$ respectively. Regarding sponsored time to degree, the junior researchers within the natural sciences, applied sciences and medical sciences attain a Ph.D. fastest (median FTTD under 4.6 years), and demonstrate highest completion rates. Ph.D. students in the social sciences take on the average more than five years to complete and have a success rate of less than $30 \%$.

Table 2: Indicators by scientific discipline: Sponsored time to degree, success and drop-out rate

\begin{tabular}{lcccccc}
\hline & $\mathrm{N}$ & $\begin{array}{c}\text { Median } \\
\text { (FTTD) }\end{array}$ & $\begin{array}{c}\text { Mean } \\
\text { (FTTD) }\end{array}$ & $\begin{array}{c}\text { SD } \\
\text { (FTTD) }\end{array}$ & $\begin{array}{c}\text { Success rate } \\
\text { (after 8 } \\
\text { years) }\end{array}$ & $\begin{array}{c}\text { Drop-out } \\
\text { rate (after 8 } \\
\text { years) }\end{array}$ \\
\hline Natural & 6,234 & 4.34 & 4.51 & 1.38 & $62.4 \%$ & $35.8 \%$ \\
Medical & 6,787 & 4.55 & 4.71 & 1.68 & $51.6 \%$ & $45.6 \%$ \\
Humanities & 4,188 & 4.81 & 5.02 & 2.01 & $36.8 \%$ & $58.7 \%$ \\
Social & 5,179 & 5.02 & 5.20 & 1.78 & $29.4 \%$ & $65.7 \%$ \\
Applied & 6,335 & 4.52 & 4.64 & 1.62 & $49.6 \%$ & $47.8 \%$ \\
\hline
\end{tabular}

Cumulative success rates during the period of the first eight financed years of the Ph.D. track, according to scientific discipline, are presented in Figure 3. Differentiation becomes clear in the fifth year: the percentage of Ph.D.'s increases the fastest in natural sciences, followed by the medical and applied sciences, while the humanities and the social sciences keep lagging. 


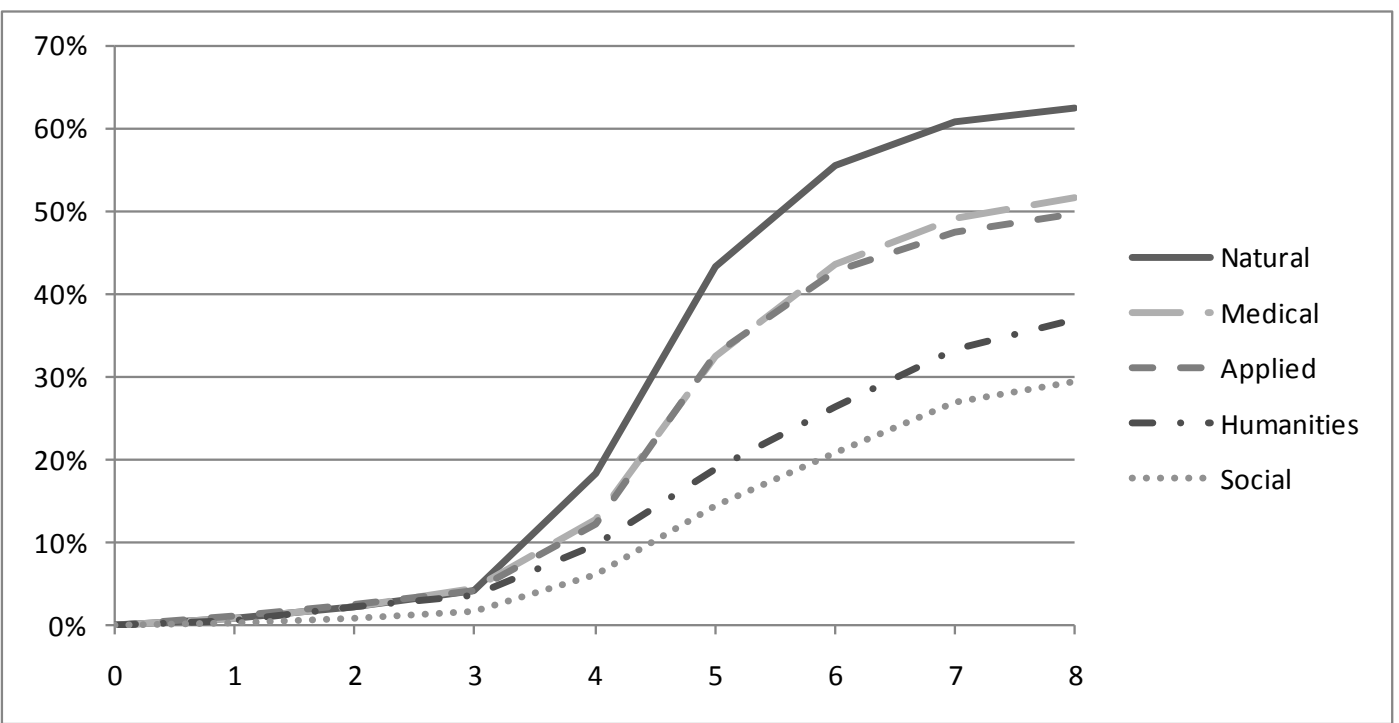

Figure 3: Cumulative success rates within a period of eight years of sponsored time, by scientific discipline

\section{Type of scholarship or appointment}

Junior researchers with an assistant lectureship require the most time to attain a Ph.D. (a median of 5.99 years, see Table 3). Both types of competitive scholarships score best, with 83.7 and $75.7 \%$ of success within 8 years. Junior researchers with project funding (other than fundamental research) have the lowest chance of success (18.0\%). As doctoral researchers often combine various types of funding consecutively, the actual sponsored type may exceed the duration of their "dominant" type of scholarship or appointment.

Table 3: Indicators by dominant type of scholarship or appointment across the junior career: Sponsored time to degree, success and drop-out rate

\begin{tabular}{lcccccc}
\hline & $\mathrm{N}$ & $\begin{array}{c}\text { Median } \\
\text { (FTTD) }\end{array}$ & $\begin{array}{c}\text { Mean } \\
\text { (FTTD) }\end{array}$ & $\begin{array}{c}\text { SD } \\
\text { (FTTD) }\end{array}$ & $\begin{array}{c}\text { Success rate } \\
\text { (after 8 } \\
\text { years) }\end{array}$ & $\begin{array}{c}\text { Drop-out } \\
\text { rate (after 8 } \\
\text { years) }\end{array}$ \\
\hline $\begin{array}{l}\text { Assistant lectureship } \\
\begin{array}{l}\text { Competitive scholarship } \\
\text { (Flanders) }\end{array}\end{array}$ & 5,806 & 5.99 & 6.02 & 1.74 & $39.1 \%$ & $54.5 \%$ \\
$\begin{array}{l}\text { Competitive scholarship } \\
\text { (own university) }\end{array}$ & 1,311 & 3.44 & 4.56 & 1.12 & $83.7 \%$ & $15.5 \%$ \\
$\begin{array}{l}\text { Project funding (FWO, } \\
\text { BOF, IUAP) }\end{array}$ & 7,931 & 4.35 & 4.78 & 1.54 & $75.7 \%$ & $22.7 \%$ \\
Project funding (other) & 8,368 & 4.00 & 4.00 & 1.96 & $18.0 \%$ & $79.8 \%$ \\
\hline
\end{tabular}

The cumulative success rates according to type of funding or appointment are presented in Figure 4. The early increase of success amongst competitive scholarships (own university) stands out. Within three years, already $15.6 \%$ attains a Ph.D. However, this group is taken over by the group of competitive scholarships (Flanders) during the fifth year. The increase of cumulative success is the slowest for assistant lectureships, with a 'delayed growth' in cumulative success during the sixth till eighth year. 


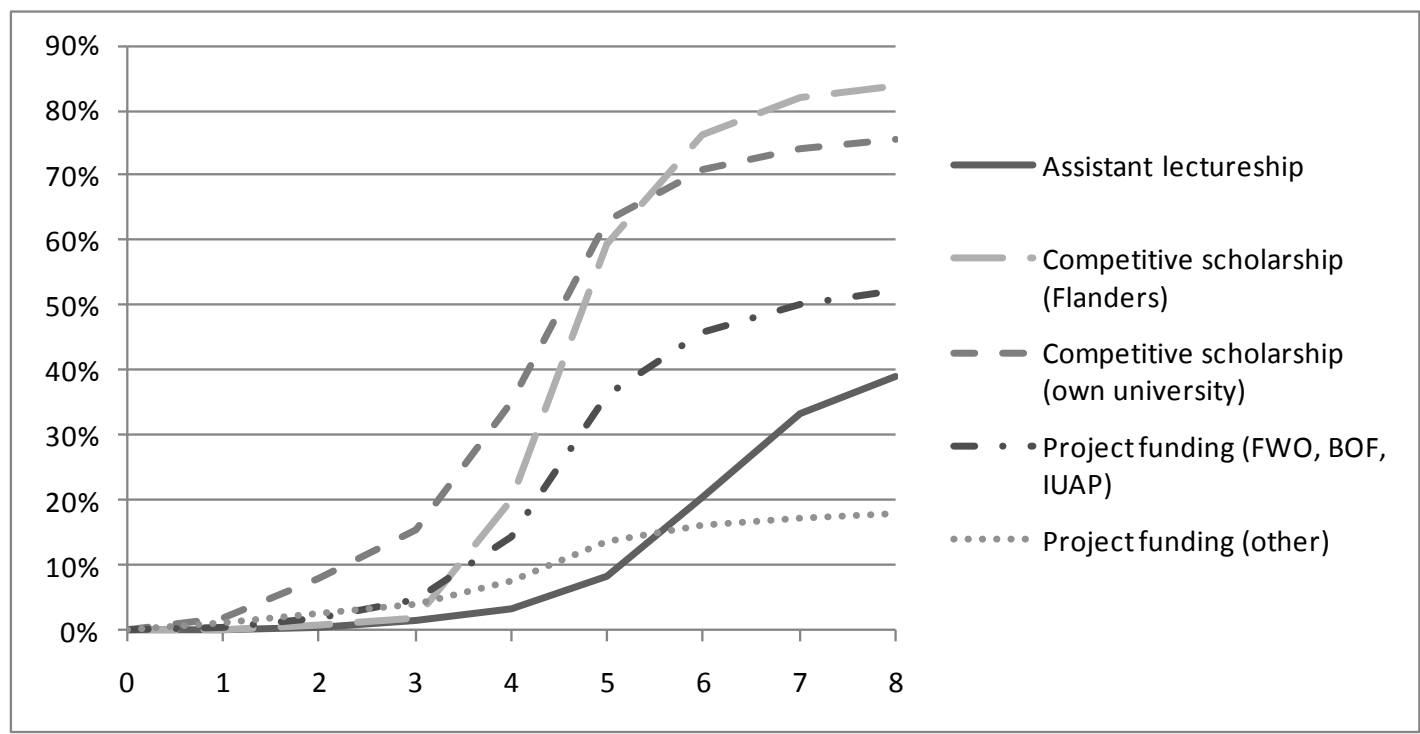

Figure 4: Cumulative success rates within a period of eight years of sponsored time, by type of scholarship or appointment

\section{Gender}

The median sponsored time does not differ much between men and women (see Table 4), but men are slightly faster (.13 years) and more successful $(5.1 \%)$ than women.

Table 4: Indicators by gender: Sponsored time to degree, success and drop-out rate

\begin{tabular}{cccccc}
$\mathrm{N}$ & $\begin{array}{c}\text { Median } \\
\text { (FTTD) }\end{array}$ & $\begin{array}{c}\text { Mean } \\
\text { (FTTD) }\end{array}$ & $\begin{array}{c}\text { SD } \\
\text { (FTTD) }\end{array}$ & $\begin{array}{c}\text { Success rate } \\
\text { (after 8 } \\
\text { years) }\end{array}$ & $\begin{array}{c}\text { Drop-out } \\
\text { rate (after 8 } \\
\text { years) }\end{array}$ \\
15,827 & 4.48 & 4.63 & 1.66 & $51.0 \%$ & $42.8 \%$ \\
13,028 & 4.61 & 4.86 & 1.64 & $46.1 \%$ & $53.8 \%$ \\
\hline
\end{tabular}

Cumulative success rates are presented in Figure 5. Overall, the patterns are very similar. The differences between men and woman remain small, but become bigger as their careers proceed over time.

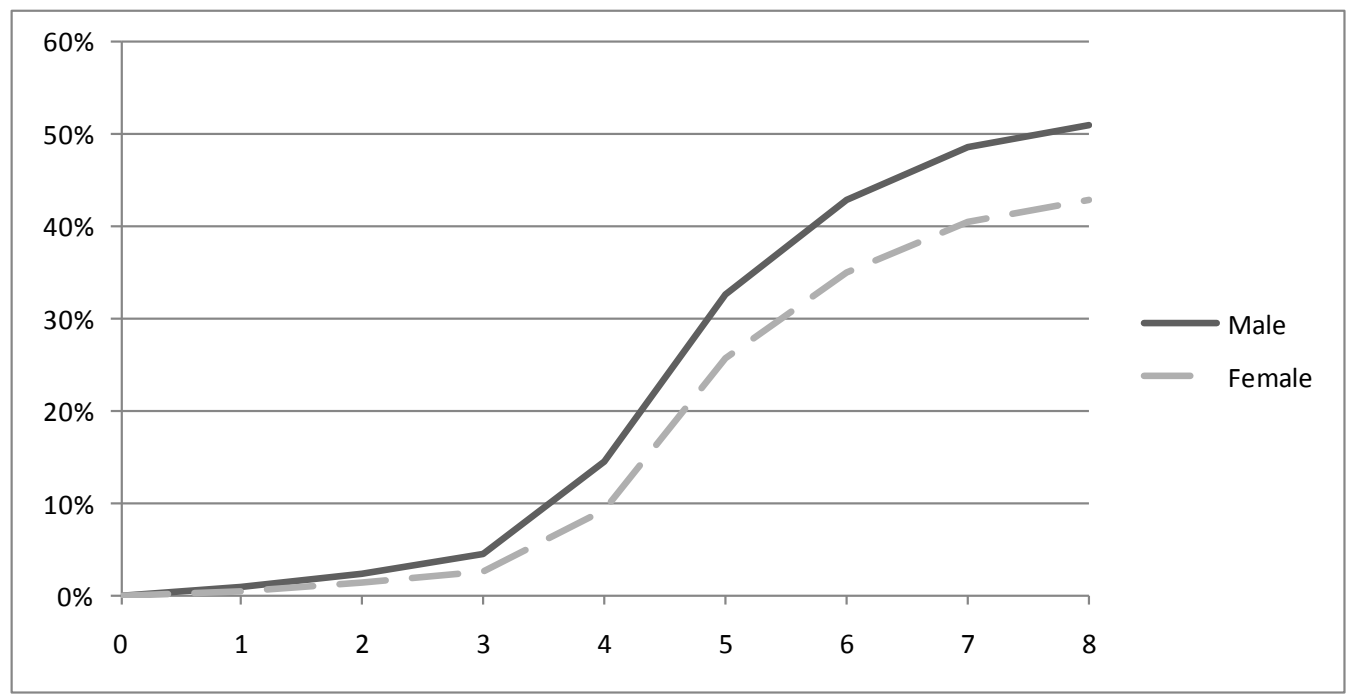

Figure 5: Cumulative success rates within a period of eight years of sponsored time, by gender 


\section{Age group}

The age of the junior researcher studied in this analysis, is the age of the researcher at the moment of 'entry' as junior researcher at a Flemish university. When comparing the five different age groups (see Table 5), the range of variation in median sponsored time to degree is rather large: 2.51 years. Older researchers are funded for a shorter period before they acquire their Ph.D. However, the group younger than 26 at the start of their research career, are the most successful (52.7\%), while researchers over 40 have a low probability of attaining a Ph.D. (19.1\%).

Table 5: Indicators by age: Sponsored time to degree, success and drop-out rate

\begin{tabular}{lrccccc}
\hline & $\mathrm{N}$ & $\begin{array}{c}\text { Median } \\
(\text { FTTD }\end{array}$ & $\begin{array}{c}\text { Mean } \\
(\text { FTTD) }\end{array}$ & $\begin{array}{c}\text { SD } \\
\text { (FTTD) }\end{array}$ & $\begin{array}{c}\text { Success rate } \\
\text { (after 8 } \\
\text { years) }\end{array}$ & $\begin{array}{c}\text { Drop-out } \\
\text { rate (after 8 } \\
\text { years) }\end{array}$ \\
\hline <26 year & 20,526 & 4.65 & 4.93 & 1.44 & $52.7 \%$ & $44.3 \%$ \\
26-30 year & 5,308 & 4.00 & 4.27 & 1.97 & $36.6 \%$ & $60.1 \%$ \\
31-35 year & 1,674 & 3.25 & 3.40 & 2.20 & $32.5 \%$ & $64.1 \%$ \\
36-40 year & 667 & 2.62 & 2.97 & 2.10 & $34.8 \%$ & $61.1 \%$ \\
$>$ 40 year & 616 & 2.14 & 2.78 & 2.14 & $19.1 \%$ & $76.4 \%$ \\
\hline
\end{tabular}

Cumulative success rates according to age are presented in Figure 6. The youngest group appears to follow another pattern than the older groups: they start slowly but surpass the other age groups by far after five financed years. The younger the researcher, the more often the 'standard' Ph.D. pattern of attaining a Ph.D. within four to six year is followed. The older the junior researcher, the more frequent both shorter and longer Ph.D. tracks can be observed.

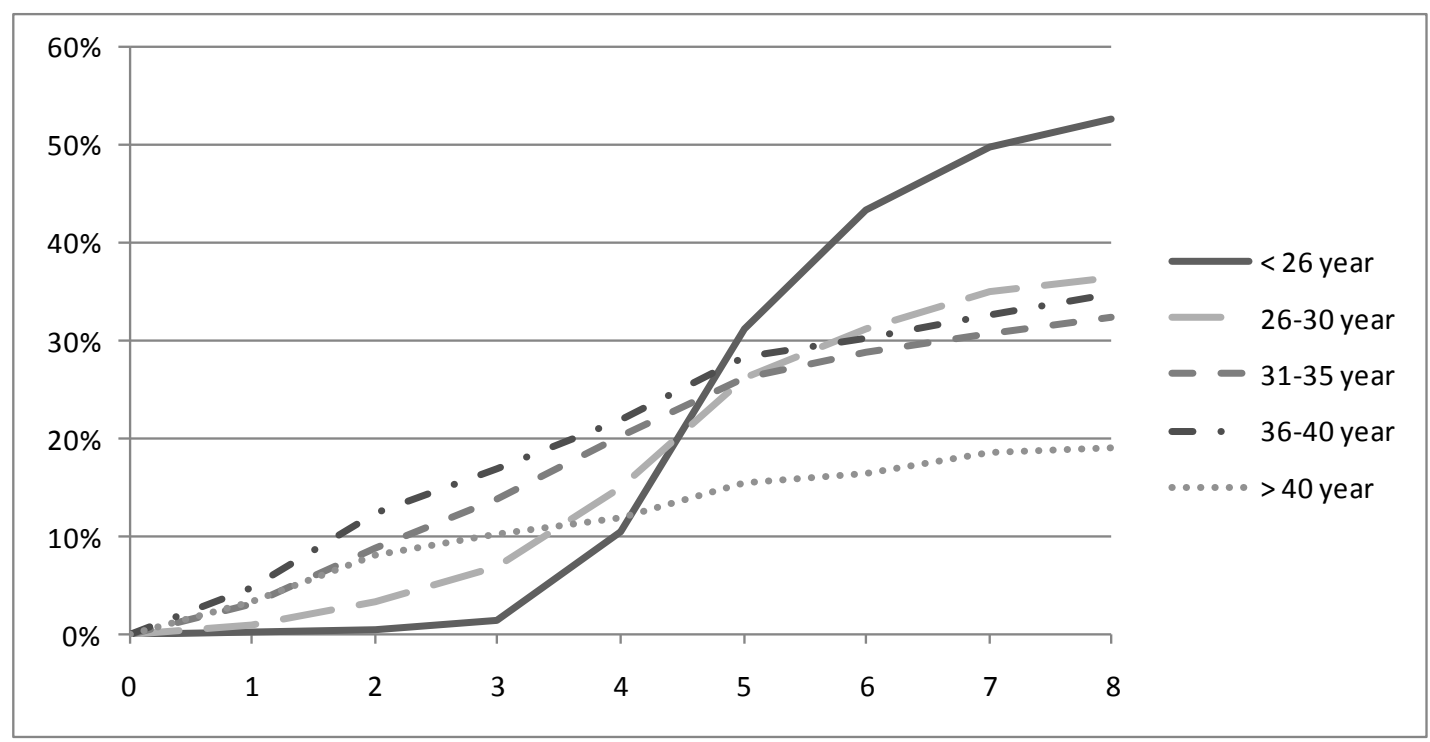

Figure 6: Cumulative success rates within a period of eight years of sponsored time, by age

\section{Nationality}

Information on possible appointments and doctoral degrees attained in other universities outside of Flanders, is not included in the HRRF database. The picture is limited to the phase of doctoral researchers' careers at a Flemish university. Therefore the odds are high that sponsored junior careers of migrating researchers (especially non-Belgians) are not fully included in this study.

Compared to the two other nationality groups, Belgian junior researchers have the longest FTTD. (see Table 6, with a difference in median of 0.67 between Belgian and other EU 
researchers and of 1.21 between Belgian and Non-EU researchers). Non-EU researchers have the highest success rates $(53.4 \%)$.

Table 6: Indicators by nationality: Sponsored time to degree, success and drop-out rate

\begin{tabular}{lrccccc}
\hline & $\mathrm{N}$ & $\begin{array}{c}\text { Median } \\
\text { (FTTD) }\end{array}$ & $\begin{array}{c}\text { Mean } \\
\text { (FTTD) }\end{array}$ & $\begin{array}{c}\text { SD } \\
\text { (FTTD) }\end{array}$ & $\begin{array}{c}\text { Success rate } \\
\text { (after 8 } \\
\text { years) }\end{array}$ & $\begin{array}{c}\text { Drop-out } \\
\text { rate (after 8 } \\
\text { years) }\end{array}$ \\
\hline Belgian researchers & 23,438 & 4.67 & 4.95 & 1.54 & $48.5 \%$ & $48.0 \%$ \\
Foreign EU researchers & 2,639 & 4.00 & 3.92 & 1.65 & $35.6 \%$ & $62.3 \%$ \\
Non EU researchers & 2,549 & 3.46 & 3.09 & 1.61 & $53.4 \%$ & $46.3 \%$ \\
\hline
\end{tabular}

The cumulative success rates according to nationality are presented in Figure 7. Belgian researchers have the lowest chance of attaining a Ph.D. within four years, but they surpass the foreign EU researchers as their research time increases.

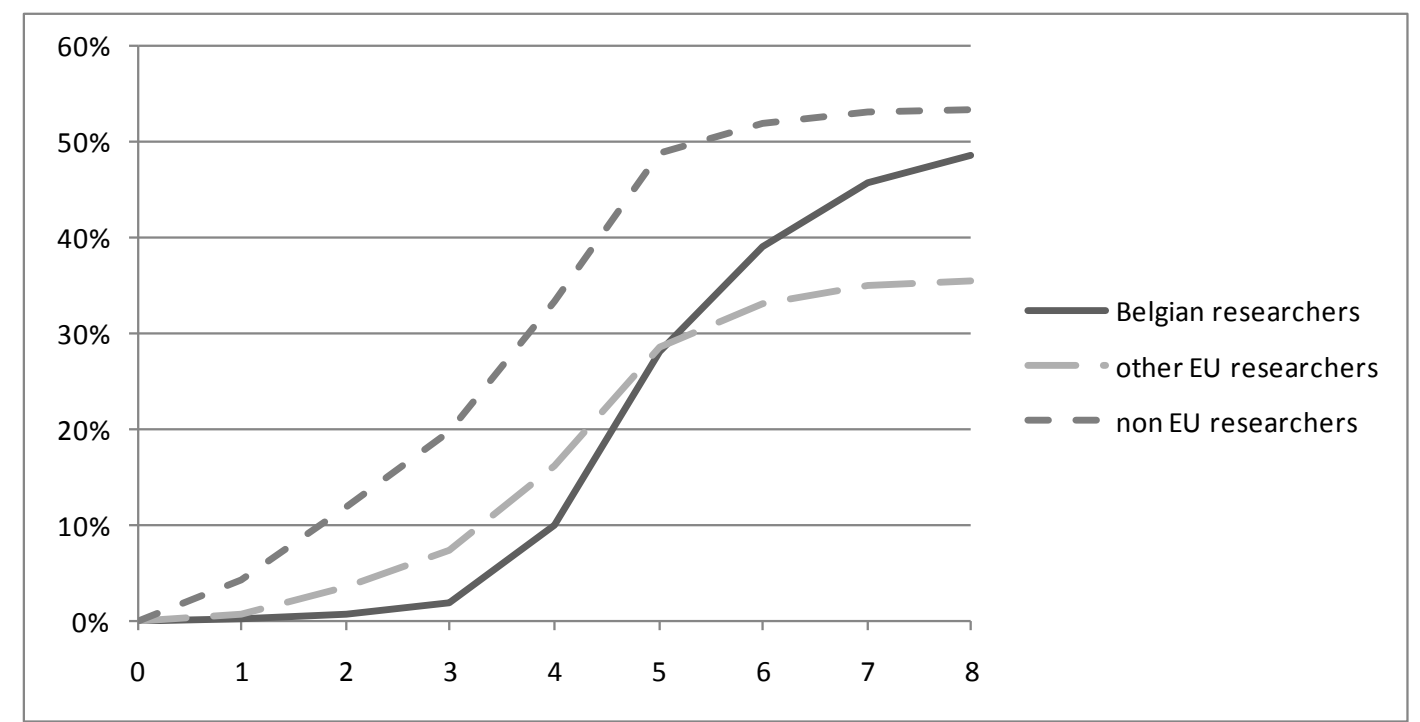

Figure 7: Cumulative success rates within a period of eight years of sponsored time, by nationality

\section{An integrated approach: Event history analysis}

Other studies on doctoral completion have seldom tackled the problem of censored data when using techniques such as correlations, chi-square tests, t-tests, analysis of variance, analysis of covariance and multiple regression (e.g. Wright \& Cochrane, 2000; Seagram, Gould, \& Pyke, 1998), at the risk of biased results or loss of information. We study both the moment of doctoral attainment and of drop-out by applying a suitable method that accounts for the censoring problem: event history analysis.

The HRRF database contains a substantial amount of right-censored data, a specific type of missing data problem. Indeed, for some individuals it is not known when an event occurs because they did not experience/have not yet experienced the event during the observation period: all junior researchers who have not yet dropped out or attained a Ph.D. at the end of the HRRF database timeframe (September $30^{\text {th }} 2009$ ) are labelled as 'still active'. Competing risks proportional hazard models allow us to examine the determinants of the time to success or failure, while taking into account the censoring of the data and the presence of correlated predictors. 
A common method of event history analysis, the Cox proportional-hazards model (Cox, 1972), was applied to the appointment data of 28,396 junior researchers ${ }^{1}$. This technique allows for determining the relative impact of each of these characteristics on the level of success/failure \& time to degree, offering explanations for the question why some individuals experience the event earlier than others (Willett \& Singer, 1993). Even more so than in the separate descriptive analyses of the impact of the various parameters on the doctoral outcome, it is relevant to study only the sponsored time in the integrated event history analysis. Periods of sickness, inactivity and pregnancy can all cause delays during the Ph.D. trajectory.

In Table 7, hazard ratios are presented for the various determinants. These ratios indicate the relative 'risk' of success or drop out compared to the reference category. A hazard ratio higher than 1 indicates a higher chance to achieve the outcome (success or drop out) in the next time unit (sponsored year), meaning a faster average attainment of the outcome. A hazard ratio lower than 1 indicates a lower chance. Each of these relative hazard ratios are controlled for all other determinants. As such we can detect the determinants that have the most significant influence on doctoral outcomes.

Cohort: The speed of doctoral attainment is the highest amongst the second cohort of inflow. The first cohort appears to be less prone to early drop out compared to the second and third cohort. Because of the high amount of censoring of the third cohort, the value of the relative hazard ratios should be considered as less reliable.

Scientific discipline: The speed of attaining a Ph.D. is the highest in the natural sciences, followed by medical and applied sciences, while the humanities and social sciences take the longest. A reverse relationship is observed when looking at the speed of drop out.

Type of scholarship or appointment: assistant lectureships take the longest to attain a Ph.D. compared to the other funding situations. Junior researchers with competitive scholarships are less likely to drop out. Especially junior researchers financed by means of applied-research projects are most likely to drop out faster.

Gender: when controlling for the other variables, women take longer to attain a Ph.D. compared to men and are prone to dropping out more quickly, although the difference is quite small.

Age group: the group older than 40 deviates strongly from the other age groups: they obtain their $\mathrm{Ph} . \mathrm{D}$. much faster. The risk of a faster drop out, however, increases with age.

Nationality: non EU junior researchers attain a Ph.D. the fastest, followed by EU junior researchers and Belgian researchers. Non EU and EU researchers run more or less the same risk of dropping out; Belgians are characterized by the lowest risk of a fast drop out.

\footnotetext{
${ }^{1}$ The number of junior researchers included in the event history analysis is slightly lower compared to the number of junior researchers included in the descriptive analyses. When applying the event history analysis, all subjects with missing data on one of the parameters are omitted from the analysis, while this is only the case for the specific parameters of focus in the descriptive analyses.
} 
Table 7: Results of the event history analysis (financed time to degree and financed time to drop- out)

\begin{tabular}{|c|c|c|c|c|c|c|}
\hline \multirow{3}{*}{$\begin{array}{c} \\
\text { Starting cohort } \\
1990-1996\end{array}$} & \multicolumn{3}{|c|}{ Financed time to degree } & \multicolumn{3}{|c|}{ Financed time to drop out } \\
\hline & $\begin{array}{c}\text { Hazard } \\
\text { ratio }\end{array}$ & \multicolumn{2}{|c|}{$\begin{array}{l}95 \% \text { confidence } \\
\text { interval }^{\mathrm{a}}\end{array}$} & $\begin{array}{c}\text { Hazard } \\
\text { ratio }\end{array}$ & \multicolumn{2}{|c|}{$\begin{array}{l}95 \% \text { confidence }^{\text {interval }}{ }^{\mathrm{a}} \\
\end{array}$} \\
\hline & 1.000 & & & 1.000 & & \\
\hline $1997-2003$ & $1.238 * * *$ & 1.183 & 1.296 & $0.749 * * *$ & 0.716 & 1.783 \\
\hline 2004-2008 & $0.907 *$ & 0.826 & 0.996 & $0.215 * * *$ & 0.199 & 0.233 \\
\hline \multicolumn{7}{|l|}{ Scientific discipline } \\
\hline Natural sciences & 1.000 & & & 1.000 & & \\
\hline Medical sciences & $0.834 * *$ & 0.788 & 0.884 & $1.082 *$ & 1.009 & 1.160 \\
\hline Humanities & $0.499 * * *$ & 0.463 & 0.537 & $1.398 * * *$ & 1.300 & 1.504 \\
\hline Social sciences & $0.512 * * *$ & 0.475 & 0.551 & $1.494 * * *$ & 1.396 & 1.599 \\
\hline Applied sciences & $0.737 * * *$ & 0.695 & 0.781 & $1.099 * *$ & 1.026 & 1.177 \\
\hline \multicolumn{7}{|l|}{ Scholarship or appointment } \\
\hline Assistant lectureship & 1.000 & & & 1.000 & & \\
\hline $\begin{array}{l}\text { Competitive scholarship } \\
\text { (Flanders) }\end{array}$ & $2.860 * * *$ & 2.689 & 3.042 & $0.344 * * *$ & 0.313 & 0.378 \\
\hline $\begin{array}{l}\text { Competitive scholarship } \\
\text { (own university) }\end{array}$ & $2.839 * * *$ & 2.570 & 3.137 & $0.507 * * *$ & 0.436 & 0.590 \\
\hline $\begin{array}{l}\text { Project funding (FWO-, } \\
\text { BOF-, IUAP) }\end{array}$ & $1.777 * * *$ & 1.668 & 1.893 & 1.053 & 0.990 & 1.120 \\
\hline Project funding (other) & $1.246^{* * *}$ & 1.149 & 1.351 & $2.859 * * *$ & 2.705 & 3.022 \\
\hline \multicolumn{7}{|l|}{ Gender } \\
\hline Male & 1.000 & & & 1.000 & & \\
\hline Female & $0.899 * * *$ & 0.861 & 0.938 & $1.110 * * *$ & 1.064 & 1.158 \\
\hline \multicolumn{7}{|l|}{ Age } \\
\hline$<26$ year & 1.000 & & & 1.000 & & \\
\hline 26-30 year & $0.914 * *$ & 0.855 & 0.977 & $1.223 * * *$ & 1.157 & 1.293 \\
\hline 31-35 year & 1.019 & 0.912 & 1.139 & $1.406 * * *$ & 1.293 & 1.528 \\
\hline $36-40$ year & 0.963 & 0.821 & 1.131 & $1.369 * * *$ & 1.210 & 1.549 \\
\hline$>40$ year & $0.617 * * *$ & 0.494 & 0.771 & $1.825^{* * *}$ & 1.624 & 2.052 \\
\hline \multicolumn{7}{|l|}{ Nationality } \\
\hline Belgian researchers & 1.000 & & & 1.000 & & \\
\hline EU researchers & $1.629 * * *$ & 1.489 & 1.782 & $1.258 * * *$ & 1.170 & 1.352 \\
\hline Non EU researchers & $3.133 * * *$ & 2.858 & 3.435 & $1.206 * * *$ & 1.103 & 1.318 \\
\hline
\end{tabular}

\section{Discussion}

All characteristics examined in this chapter relate to differences in success and drop out, addressing 'the measure of' as well as 'the speed of'. Comparing the results of the descriptive analysis and the more integrated approach of event history analysis, the 'measure of' and the 'speed of' the doctoral process appear to be strongly related. The following groups of junior researchers have the greatest chance of obtaining a doctorate degree, as well as have the chance to achieve it the fastest: the cohort 1997-2003, those in the natural, medical and applied sciences, those having a competitive scholarship, who are male, younger than 26 at the start, and those who are non-EU researchers. In contrast, the group of junior researchers 
most likely to drop out or to drop out the fastest are: the cohort 1990-1996, the social sciences and humanities, being funded with projects of applied research, being female, older than 40 at the time of first scientific contact and being a foreigner from within the EU. While all of the selected characteristics appear to have a significant influence on measure and speed of success and drop out, a junior researcher's scientific discipline and the type of scholarship or appointment are the most important factors for predicting success in achieving the doctorate.

Differences between cohorts might be an indicator of policy-driven interventions in the research \& education system. When the final cohort will contain fewer censored data (cf. future HRRF-updates), it will be possible to fully examine the way in which completion rates develop. As for now, we cannot fully evaluate whether a positive development demonstrates a more effective use of Ph.D. funding following strong government incentives to increase the number of Ph.D. degrees at Flemish universities (Spruyt \& Rons, 2008). ${ }^{2}$

Differences between types of appointments or scholarship are mainly due to their varying levels of prestige and to their corresponding hierarchy in terms of research autonomy and job security. The selection process preceding competitive scholarships reserves this appointment status for students with high grades at previous educational levels, who are highly motivated, and who have a supervisor's support before even starting their research work. Therefore, the type of funding may to a certain extent be a proxy for previous educational performance or may be confounded with a 'grooming culture' in which certain groups or types of students are more easily encouraged/supported to enter into doctoral training. Researchers with competitive scholarships also tend to have more autonomy in their research and to be less burdened by teaching and administrative responsibilities. An increasing number of researchers first accept a temporary project-funded Ph.D. position before applying for these four-year competitive scholarships, which explains why times-to-degree according to 'dominant' funding situation are often higher than the duration of the scholarship itself. Those who remain in temporary project-funded contracts, especially when these projects involve applied or policy-relevant research, often experience less job security and less autonomy to focus on their doctoral research. Their completion rates are lower and time-to-degree longer. Assistant lectureships are awarded for 6 years and generally provide $50 \%$ research time, which explains the much longer time-to-degree for this category. Their remaining time is devoted to teaching and administrative support to the department, which might put these Ph.D. students in a vulnerable position being burdened with time-consuming tasks not related to their Ph.D. project. If researchers need more than the duration of their funding, this extra time is eliminated in the current analyses based on sponsored time, but could easily be determined when comparing with calendar time.

Field-specific variation can be attributed mainly to differences in academic practice: $\mathrm{Ph} . \mathrm{D}$. researchers in the natural sciences more often work as part of a team within a specific, predesigned project, and operate within a quality framework more often defined by transparent quantitative publication criteria (Larivière, 2012), all of which might provide more reassurance and guidance to researchers new to the job. For researchers in the humanities and social sciences, establishing one's own research idea (and thus often working in isolation) may constitute more of a challenge in terms of perseverance, not to mention the lack of consensus over quality criteria in these fields (Long \& Fox, 1995). Also the extent to which a

\footnotetext{
${ }^{2}$ Since 2000 , the number of doctoral degrees has taken up a large share in the Flemish interuniversity allocation key for research funding - a parameter currently accounting for $35 \%$.
} 
Ph.D. degree is a bonus in the labour market (more so for natural scientists, biomedical experts and engineers, less so for graduates in humanities and social sciences) may affect the intention to start a Ph.D. or the intention to complete or to drop out from the programme (Groenvynck et al, 2011). Some confounding between field and type of scholarship may occur, as natural sciences, medical sciences and applied sciences have a larger share of competitive scholarships in Flanders, while assistant lectureships are more common in humanities and social sciences.

Gender balance has been obtained at entry level into Flemish doctoral programmes, although unevenly spread across disciplines. When controlling for this uneven spread, however, women do not perform as well as men in terms of doctoral success. With the exception of Booth and Satchell (1995), other studies performed elsewhere show little or no gender difference in completion probability (Mastekaasa, 2005; Baker, 1998; Ehrenberg \& Mavros, 1995), suggesting either that other contextual elements not included in these models have an additional impact, or that the leaky pipeline phenomenon for women in scientific careers (Long \& Fox, 1995) might start at an earlier stage in Flanders than in other countries.

Ph.D. researchers from outside the E.U. obtain success more often and faster than other researchers. They usually have already crossed more hurdles to be able to enter in doctoral programmes from outside the EU, often having performed preparatory research before registering at a Flemish university, and have visa restrictions pushing them to complete within the time foreseen by their scholarship. No explanation could be found why other E.U. researchers perform more poorly at Ph.D. level than Belgian researchers.

Monitoring the production of doctorate degrees and identifying the relative impact of particular factors of success can make a strong contribution to research policy. Its value lies in the fact that the analysis is based on complete and accurate register data from more than one university, and is unaffected by possible biases or low response levels often affecting survey results. Every institution with a reasonably good administrative database is in a position to adopt these methods. Although success and failure are also determined by individual factors not discussed in this paper, important differences on a group level ought to be taken into account for an appropriate system of supervision and doctoral programmes. If universities wish to minimize drop-out rates, the above analysis determines the target groups to which an incentive policy would make the greatest difference.

Future research including other variables can help finding other determinants that might predict time to degree and drop-out. A further step would be to combine administrative registration data with other databases such as institutional repositories or bibliometric data. Also possible interaction between characteristics could be explored, such as the interaction between gender and scientific discipline, and the way in which scientific practices, which vary across fields, change over time.

\section{References}

Ampaw, F. D., \& Jaeger, A. J. (2011). Understanding the factors affecting degree completion of doctoral women in the science and engineering fields. New Directions for Institutional Research, 152, 59-73.

Baker, J. G. (1998) Gender, race and Ph.D. completion in natural science and engineering. Economics of Education Review 17 (2) 179-188. 
Bradley, K. (2000). The Incorporation of Women into Higher Education: Paradoxical Outcomes? Sociology of Education 73 (1), 1-18.

Cox, D. R. (1972). Regression models and life-tables. Journal of the Royal Statistical Society, Series B (Methodological), 34(2), 187-220.

Ehrenberg, R. G., \& Mavros, P. G. (1995). Do doctoral students financial-support patterns affect their times-to-degree and completion probabilities. Journal of Human Resources, 30(3), 581-609.

Espenshade, T. J., \& Rodrigues, G. (1997). Completing the Ph.D.: Comparative performance of U.S. and foreign students. Social Science Quarterly, 78, 593-605.

Groenvynck, H. et al (2011) Doctoraatstrajecten in Vlaanderen. 20 jaar investeren in kennispotentieel. Een analyse op basis van de HRRF-databank (1990-2009). Academia Press.

Hoffer, T.B. and Welch, V. Jr. (2006): Time to Degree of U.S. Research Doctorate Recipients. National Science Foundation. Arlington, VA.

Larivière, V. (2012). On the shoulders of students? The contribution of $\mathrm{PhD}$ students to the advancement of knowledge. Scientometrics, 90, 463-481.

Long, J.S. \& Fox, M.F. (1995). Scientific Careers: Universalism and Particularism. Annual Review of Sociology (21) 45-71.

Mastekaasa, A. (2005). Gender differences in educational attainment: The case of doctoral degrees in Norway. British Journal of Sociology of Education, 26(3), 375- 394.

Seagram, B. C., Gould, J., \& Pyke, S. W. (1998). An investigation of gender and other variables on time to completion of doctoral degrees. Research in Higher Education, 39(3), 319-335.

Spruyt, E. \& Rons, N. (2008). Belonend onderzoek financieren - De BOF-sleutel, een staaltje sleutelkunde. Delta 5, 25-32.

Tekle, F. B., \& Vermunt, J. K. (in press). Event history analysis. APA Handbook of Research Methods in Psychology.

Tuckman, H., Coyle, S., \& Bae, Y. (1990). On Time to the Doctorate. Washington, DC: National Academy Press.

Visser, M. S., Luwel, M. \& Moed, H. F. (2007). The attainment of doctoral degrees at Flemish Universities: a survival analysis. Higher Education 54 (5), 741-757.

Wao, H. O. (2010). Time to the doctorate: Multilevel discrete-time hazard analysis. Educational Assessment, Evaluation and Accountability, 22, 227-247.

Wright, T. \& Cochrane, R. (2000). Factors Influencing Successful Submission of Ph.D. Theses, Studies in Higher Education, 25 (2) 182-195. 